\title{
Changes in CD4 and CD8 after Interventional Management of Hepatocellular Carcinoma
}

\author{
Walid El-Sherbiny ${ }^{1}$, Nashwa Khairat Abousamra ${ }^{2}$, \\ Muhammad Diasty ${ }^{1}$, Shaker Wagih Shaltout ${ }^{1}$ \\ ${ }^{1}$ Tropical Medicine Department, Faculty of Medicine, Mansoura University, Egypt. \\ ${ }^{2}$ Clinical Pathology Department, Faculty of Medicine, Mansoura University, Egypt.
} Corresponding Author
Walid El-Sherbiny

Mobile:

$+201009092903$

E mail:

walidelsherbiny1@yahoo. com

Key words:

CD4, CD8, CD4/CD8 ratio, Hepatocellular carcinoma ablation, RFA, PEI, TACE, $M W A$
Background and study aim : Hepatocellular carcinoma (HCC) has many curative choices which in some circumstances are equal to or even better than surgery. These strategies for treatment of HCC may induce certain local effects which trigger distinct immunological responses that may have a systemic impact on the natural history of the tumour itself. These responses are validated through the measurement of specific immune cells in the systemic circulation. In this study, we tried to observe and analyze changes in the peripheral immune cells that accompany and follow HCC ablation by different procedures of radiological intervention and compare our results with literature. So, this study may be useful with other criteria in the guidelines for the selection of the optimal therapeutic strategy for each patient.

Patients and Methods: This study was conducted on about 50patients diagnosed with HCC who were referred to Tropical Medicine Department at Mansoura University Hospital, Egypt and 20 healthy volunteers as a control. The therapeutic strategy was selected according to the tumor stage and general condition. RFA was performed for 12 cases, PEI for 13, MWA for 12 and TACE for 13 cases. All Patients were subjected to full history taking, clinical examination, liver function tests, anti HCV antibodies and HBS antigen by 3rd generation ELISA, serum alpha

\section{INTRODUCTION}

Hepatocellular Carcinoma (HCC) is currently the sixth most prevalent cancer worldwide and the third leading cause of cancer-related death [1]. It is one of the leading causes of morbidity and mortality in patients with liver cirrhosis. Furthermore, it has a rapidly rising incidence, largely driven by the burden of advanced Hepatitis C Virus (HCV) fetoprotein, abdominal ultrasonography, triphasic abdominal computerized tomography and lymphocyte subset assay by flow cytometry 1 day before, and 3 weeks after the treatment.

Results: Regarding the immunological status between control and HCC patients, there was a demonstrable difference in the number of cells in both groups, as the control group had higher levels of CD4+ and CD8+ values. In the RFA group, CD4+ cells and CD4/CD8 ratio remarkably increased after treatment $(\mathrm{P}<0.001)$, and the CD8+ cells significantly decreased (P $<0.002$ ) with concomitant increase in the $\mathrm{CD} 4+/ \mathrm{CD} 8+$ ratio $(\mathrm{P}<0.001)$. In the PEI group, CD4+ cells markedly increased after treatment $(\mathrm{P}<0.001)$, but there were no significant differences in CD8+ cells and $\mathrm{CD} 4 / \mathrm{CD} 8$ ratio. In the MWA group, CD4+ cells markedly increased after treatment $(\mathrm{P}<0.001)$, with increase in $\mathrm{CD} 4 / \mathrm{CD} 8$ ratio $(\mathrm{P}<0.007)$ but there were no significant differences in CD8+ cells. In the TACE group, the CD4+ cells and CD4/CD8 ratio dramatically decreased after treatment $(\mathrm{P}<0.001)$, and the CD8+ cells increased significantly $(\mathrm{P}<0.001)$.

Conclusion: Our study has proved to find a relationship between immunity and different models of therapy in HCC patients and demonstrated a positive attitude towards increasing immune cells following ablation technique.

and non-alcoholic steatohepatitis (NASH) cases [2].

Prognosis for patients with HCC depends on tumor stage at diagnosis, with curative options available only for patients diagnosed at an early stage $[3,4]$. Unfortunately, two thirds of patients with HCC are diagnosed at an advanced stage, when curative options no longer exist and median survival is less than 1 year [5]. 
Local ablative therapies such as radiofrequency ablation (RFA), percutaneous ethanol injection (PEI) and Microwave coagulation therapy (MWA) offer potential cure for tumors detected at an early stage in well selected patients. For intermediatestage HCC, transarterial chemoembolization (TACE) is the mainstay of treatment [6]. Also; RFA combined with TACE is an efficient and safe treatment that provides overall survival rates similar to those achieved with surgical resection [7].

Previous studies have shown that immune responses are inevitable in HCC and the lymphocytes phenotype and proportion are being valuable in predicting the response and prognosis in HCC [8-9]. Studies have shown a significant increase in frequency of regulatory $\mathrm{T}$ cells in peripheral blood, tumor and ascites of HCC patients [8]. Although, naturally occurring anti-tumour immune responses could be detected in patients with HCC, this response fails to control tumour growth. This failure could be because of the suppressive effects exerted by the tumour cells on antitumour immune responses [11].

Ablative techniques share, irrespective of their mechanism of induction of cell death, the ability to stimulate the immune system [12]. Interventional therapeutic procedures produce local and systemic effect capable of inducing cellular infiltration which in turn has the ability to mediate immunological response capable of combating tumour growth and proliferation [13]. These valuable data could lead us in the future to create the so-called tumor vaccination.

This study aimed to investigate changes in the peripheral immune cells of HCC patients following treatment with different interventional strategies including RFA, MWA, TACE and PEI. So, this study may be useful with other criteria in guidelines for the selection of optimal therapeutic strategy for each patient.

\section{PATIENTS AND METHODS}

This study was a prospective interventional (Randomized Control Trial) study. It was conducted on 50 patients selected from 65 patients diagnosed with HCC who were referred to Tropical Medicine Department at Mansoura University Hospital, Egypt. The study included20 subjects as control. Patients with HCC were 31 males and 19 females and their age ranged from 42 years to 66 years with mean age of $(58.42 \pm 5.42)$. According to
Child-Turcotte-Pugh classification, 34 patients were classified as class A and 16 as class B.

HCC diagnosis was confirmed by triphasic abdominal computerized tomography scan or dynamic contrast-enhanced MRI. Diagnosis was based on the identification of the typical hallmark of HCC (hypervascular in the arterial phase with washout in the portal venous or delayed phases).

The inclusion criteria were as follows: (i) Patients exhibiting good compliance and providing informed consent, (ii) Patients with primary HCC and naïve to treatment. (iii)Patients with liver cirrhosis of Child-Pugh class A or B .About 15 patients were excluded from the study because they had one or more of the following exclusion criteria: Patients with metastatic tumor, patients with liver cirrhosis of Child- Pugh class $\mathrm{C}$ and patients who refused to participate in the study.

This study included 2 main groups: Group A: included 20 healthy control individuals, Group B: included 50 HCC patients. Group B was subdivided into 4 subgroups, subgroup 1(RFA group): Patients in this group were treated with radiofrequency ablation, subgroup2 (MWA group): Patients in this group were treated with microwave ablation, subgroup 3(PEI group): Patients in this group were treated with percutaneous ethanol injection and subgroup4 (TACE group): Patients in this group were treated with transarterial chemoembolization therapy. An informed consent was obtained before patients were enrolled in the study.

All participants in both groups were subjected to full history taking, clinical examination (general and abdominal examination), liver function tests (serum albumin level, serum bilirubin level and international normalized ratio), anti $\mathrm{HCV}$ antibodies and HBS antigen by 3rd generation ELISA, serum alpha fetoprotein level(AFP) ,abdominal ultrasonography, triphasic abdominal computerized tomography and lymphocyte subset assay.

\section{Lymphocyte subset assay:}

Peripheral blood samples from patients (after obtaining informed consent and Institutional Review Board approval) were collected 1 day before treatment and three weeks after treatment in EDTA contaiming tubes. After incubation of blood sample with a mixture of fluorescence labeled anti-CD3, and anti-CD8 monoclonoal antibodies for 15 minutes, lysis of red blood cells was done using 10Test 3 lysis solution (Immunotech, Beckman Coulter, Marseille, France). Analysis 
was done using the EPICS XL flow cytometer (Coulter Electronic, Fl, USA). For all flow cytometric analysis each sample was run with an appropriate isotype control (Mouse IgG, Dakocytoformation, Denmark) to define the negatively stained cells. The following antibodies were used: fluorescein isothiocyanate (FITC)-labeled antiCD3,R-phycoerythrin-cyanine 5 (RPE-CY5)labeled anti-CD4, phycoerythrin (PE)-labeled anti-CD8. The antibodies were purchased from immunotech, Beckman Coulter, Marseille, France.

\section{Statistical analysis}

Data were analyzed with SPSS version 21 . The normality of data was first tested with onesample Kolmogorov-Smirnov test. Qualitative data were described using number and percent. Association between categorical variables was tested using Chi-square test. Continuous variables were presented as mean \pm SD (standard deviation). The two groups were compared with Student $t$ test while paired t- test were used to compare paired data. Analysis Of Variance (ANOVA test) used for comparison of means of more than two groups.

\section{RESULTS}

This study was conducted on 50 patients selected from 65 patients diagnosed with HCC. They were 31 males (62\%) and 19 females (38\%) and their age ranged from 42 years to 66 years with mean age of (58.42 \pm 5.42$)$. According to ChildTurcotte-Pugh classification, 34 patients were classified as class A and 16 as class B.

In our study, the correlation between the child score and immunological condition of patients was statistically non-significant.
Most of patients had HCV infection (49), and only one patient had HBV as a cause of liver cirrhosis and HCC subsequently (Table1).

Our patients performed a variety of clinical interventional procedurs including RFA (12), PEI (13), MWA (12) and finally TACE (13). All patients survived to the date of follow up with no major complications or morbidity (Fig. 1).

Regarding the immunological status between control and HCC patients, their was a demonstratable difference in the number of cells in both groups, as the control group had higher levels of CD4+ and CD8+ values (Table 2).

Changes in the lymphocyte subset after treatment in the subgroups of HCC patients are shown in Table 3 which demonstrate the tendency of partial variables changes. In the RFA group, CD4+ cells and $\mathrm{CD} 4 / \mathrm{CD} 8$ ratio remarkably increased after treatment $(\mathrm{P}<0.001)$, and the $\mathrm{CD} 8+$ cells significantly decreased $(\mathrm{P}<0.002)$ with concomitant increase in the $\mathrm{CD} 4+/ \mathrm{CD} 8+$ ratio $(\mathrm{P}<0.001)$. In the PEI group, CD4+ cells markedly increased after treatment $(\mathrm{P}<0.001)$, but there were no significant differences in CD8+ cells and CD4/CD8 ratio. In the MWA group, CD4+ cells markedly increased after treatment $(\mathrm{P}<0.001)$, with increase in $\mathrm{CD} 4 / \mathrm{CD} 8$ ratio $(\mathrm{P}<0.007)$ but there were no significant differences in CD8+ cells. In the TACE group, the CD4+ cells and CD4/CD8 ratio dramatically decreased after treatment $(\mathrm{P}<0.001)$, and the $\mathrm{CD} 8+$ cells increased significantly $(\mathrm{P}<0.001)$.

Statistical comparison between all subgroups shows significant decrease in the levels of AFP after treatment in The PEI group, MWA group and TACE group. $(\mathrm{P}=0.05,0.033$ and 0.043 respectively). The levels of AFP after treatment also decreased in RFA group but this decrease was statistically non-significant $(\mathrm{P}=0.136)$ (Table 4). 
Table (1) : Demographic data of HCC patients.

\begin{tabular}{|c|c|c|c|c|c|c|c|c|c|c|}
\hline & \multicolumn{2}{|c|}{ RFA (n=12) } & \multicolumn{2}{|c|}{ PEI(n=13) } & \multicolumn{2}{|c|}{$\operatorname{MWA}(n=12)$} & \multicolumn{2}{|c|}{ TACE $(n=13)$} & \multirow{2}{*}{$\begin{array}{l}\text { Total } \\
\text { No }\end{array}$} & \multirow[t]{2}{*}{$P$ value } \\
\hline & No & $\%$ & No & $\%$ & No & $\%$ & No & $\%$ & & \\
\hline \multicolumn{11}{|l|}{ Sex } \\
\hline Male & 7 & 58.3 & 5 & 38.5 & 9 & 75.0 & 10 & 76.9 & 31 & \multirow{2}{*}{$\begin{array}{l}X^{2}=5.215 \\
P=0.157\end{array}$} \\
\hline Female & 5 & 41.7 & 8 & 61.5 & 3 & 25.0 & 3 & 23.1 & 19 & \\
\hline \multicolumn{11}{|l|}{ Age } \\
\hline $\begin{array}{l}\text { Mean } \pm \\
\text { SD }\end{array}$ & \multicolumn{2}{|c|}{$57.50 \pm 6.01$} & \multicolumn{2}{|c|}{$59.84 \pm 5.91$} & \multicolumn{2}{|c|}{$58.33 \pm 4.94$} & \multicolumn{2}{|c|}{$57.92 \pm 5.13$} & & \multirow[t]{2}{*}{$\begin{array}{l}F=0.436 \\
P=0.728\end{array}$} \\
\hline $\begin{array}{l}\text { Min- } \\
\text { Max }\end{array}$ & \multicolumn{2}{|c|}{$42-63$} & \multicolumn{2}{|c|}{$45-66$} & \multicolumn{2}{|c|}{$50-66$} & \multicolumn{2}{|c|}{$50-66$} & & \\
\hline \multicolumn{11}{|c|}{ Etiology } \\
\hline $\mathrm{HCV}$ & \multicolumn{2}{|c|}{12} & \multicolumn{2}{|c|}{13} & \multicolumn{2}{|c|}{12} & \multicolumn{2}{|c|}{12} & 49 & \\
\hline $\mathrm{HBV}$ & \multicolumn{2}{|c|}{0} & \multicolumn{2}{|c|}{0} & \multicolumn{2}{|c|}{0} & \multicolumn{2}{|c|}{1} & 1 & \\
\hline \multicolumn{11}{|c|}{ Child classification } \\
\hline $\mathrm{A}$ & 10 & 83.3 & 6 & 46.2 & 6 & 50.0 & 12 & 92.3 & 34 & $X^{2}=.465$ \\
\hline$\overline{\mathrm{B}}$ & 2 & 16.7 & 7 & 53.8 & 6 & 50.0 & 1 & 7.7 & 16 & $\mathrm{P}=.024 *$ \\
\hline
\end{tabular}

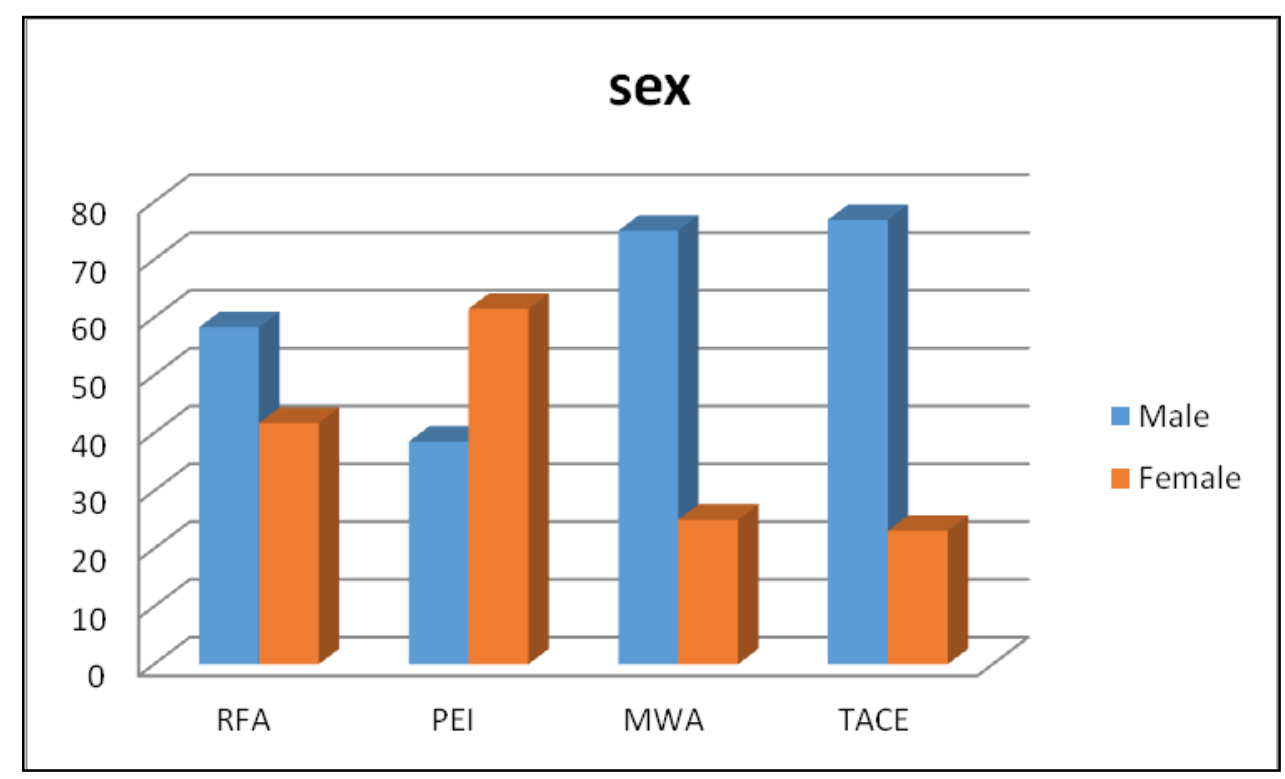

Fig. (1) : Different used methods of ablation

Table (2) : Difference between CD4+ and CD8+ in control and HCC patients

\begin{tabular}{|r|c|c|c|}
\hline GROUP & CD4+ & CD8+ & CD4/CD8 ratio \\
\hline Control & $44.61 \pm 4.2$ & $31.1 \pm 5.51$ & $1.4775 \pm 0.07$ \\
\hline $\begin{array}{r}\text { HCSt of sig. } \\
\text { p-value }\end{array}$ & $35.26 \pm 7.15$ & $29.72 \pm 6.77$ & $1.2480 \pm 0.05$ \\
\hline
\end{tabular}


Table (3) : Immune cells before and after ablation procedures.

\begin{tabular}{|c|c|c|c|}
\hline \multirow{2}{*}{ Items } & Before & After & \multirow{2}{*}{$\begin{array}{l}\text { Test of sig. } \\
\text { p-value }\end{array}$} \\
\hline & Mean \pm SD & Mean \pm SD & \\
\hline \multicolumn{4}{|l|}{ RFA group } \\
\hline CD4 & $34.41 \pm 5.68$ & $43.93 \pm 4.42$ & $\begin{array}{l}\text { Paired t-test }=4.902 \\
\mathrm{P}=\leq .001^{*}\end{array}$ \\
\hline CD8 & $32.94 \pm 6.22$ & $28.27 \pm 5.18$ & $\begin{array}{l}\text { Paired t-test }=4.027 \\
\mathrm{P}=.002 *\end{array}$ \\
\hline CD4/CD8 & $1.08 \pm 0.24$ & $1.61 \pm 0.39$ & $\begin{array}{l}\text { Paired } \mathrm{t} \text {-test }=4.658 \\
\mathrm{P}=.001^{*}\end{array}$ \\
\hline \multicolumn{4}{|l|}{ PEI group } \\
\hline CD4 & $32.5 \pm 7.24$ & $40.09 \pm 5.66$ & $\begin{array}{l}\text { Paired t-test }=5.316 \\
\mathrm{P}=\leq .001 *\end{array}$ \\
\hline $\mathrm{CD} 8$ & $26.87 \pm 7.64$ & $28.67 \pm 6.22$ & $\begin{array}{l}\text { Paired } t \text {-test }=1.156 \\
\mathrm{P}=.270\end{array}$ \\
\hline CD4/CD8 & $1.27 \pm 0.36$ & $1.50 \pm 0.59$ & $\begin{array}{l}\text { Paired } t \text {-test }=1.715 \\
\mathrm{P}=.112\end{array}$ \\
\hline \multicolumn{4}{|l|}{ MWA group } \\
\hline CD4 & $31.7 \pm 3.67$ & $39.89 \pm 3.98$ & $\begin{array}{l}\text { Paired t-test }=6.989 \\
\mathrm{P}=\leq .001\end{array}$ \\
\hline CD8 & $30.23 \pm 6.23$ & $31.81 \pm 6.31$ & $\begin{array}{l}\text { Paired t-test }=.981 \\
\mathrm{P}=.348\end{array}$ \\
\hline $\mathrm{CD} 4 / \mathrm{CD} 8$ & $1.09 \pm 0.26$ & $1.30 \pm 0.28$ & $\begin{array}{l}\text { Paired t-test }=3.301 \\
\mathrm{P}=.007 *\end{array}$ \\
\hline \multicolumn{4}{|l|}{ TACE group } \\
\hline CD4 & $42.11 \pm 6.47$ & $35.5 \pm 7.70$ & $\begin{array}{l}\text { Paired t-test }=4.699 \\
\mathrm{P}=.001 *\end{array}$ \\
\hline CD8 & $29.11 \pm 6.15$ & $34.86 \pm 6.94$ & $\begin{array}{l}\text { Paired t-test }=4.459 \\
\mathrm{P}=.001 *\end{array}$ \\
\hline CD4/CD8 & $1.52 \pm 0.45$ & $1.07 \pm 0.38$ & $\begin{array}{l}\text { Paired } \mathrm{t} \text {-test }=4.348 \\
\mathrm{P}=.001^{*}\end{array}$ \\
\hline
\end{tabular}

Table (4) : AFP before and after ablation procedures.

\begin{tabular}{|l|c|c|c|c|}
\hline \multicolumn{1}{|c|}{} & RFA & PEI & MWA & TACE \\
\cline { 2 - 5 } & Mean \pm SD & Mean \pm SD & Mean \pm SD & Mean \pm SD \\
\hline AFP before & $43.25 \pm 69.73$ & $48.30 \pm 53.75$ & $63.22 \pm 65.88$ & $75.13 \pm 134.95$ \\
\hline AFP after & $14.859 \pm 19.98$ & $25.71 \pm 23.20$ & $36.23 \pm 32.65$ & $39.08 \pm 87.61$ \\
\hline $\begin{array}{c}\text { Test of sig. } \\
\text { p-value }\end{array}$ & 0.136 & 0.053 & 0.033 & 0.043 \\
\hline
\end{tabular}

\section{DISCUSSION}

For many years, HCC was regarded as a fatal tumour that has no curative treatment except for surgery, which unfortunately was a rare possibility since we are dealing with a cirrhotic liver with all its surgical limitations and morbid systemic effects, however, in recent years the view has dramatically changed and nowadays we have many curative choices which in some circumstances are equal to and even better than surgery. Hepatic interventional procedures are now considered as a cornerstone in management of HCC due its feasibility, relative safety and affordable cost.

The effect of these procedures is not limited to tumour ablation only, but extends to another immunological local and systemic effect [14]. Ablation of tumour cells leads to hepatocyte death, formation of necrotic tissue and establishment of chemical debris, this enhancing 
environment confers the release of certain chemicals and cytokines which in turn stimulates immunity and causes sensitization of cellular antigen presentation leading to abortion of further tumour growth and even disappearance of small malignant collections [15].

In this study, we tried to observe and analyze changes in the peripheral immune cells that accompany and follow HCC ablation by different procedures of radiological intervention and compare our results with literature.

Most of HCC lesions were caused by liver cirrhosis due to HCV infection; this is explained by the fact that our community has one of the highest rates of $\mathrm{HCV}$ infection worldwide $[16,17]$.

When patients with untreated HCC compared with healthy subjects, they expressed a state of immunological impairment manifested by decreased level of $\mathrm{CD} 4+$ and $\mathrm{CD} 4 / \mathrm{CD} 8$ ratio with no significant change on CD8+ level. Guan et al, in their study has demonstrated alteration of the immune function following any change of lymphocyte subsets [13]. In our study, lymphocytes have significantly changed after ablation according to the method used.

Among the RFA group, 12 patients underwent ablation most of them were Child A (10 patients). All parameters were changed following ablation, there was significant increase in CD4+ and $\mathrm{CD} 4 / \mathrm{CD} 8$ ratio $(\mathrm{P}<0.001)$ which means a strong immunological response due to the presence of necrotic cell death which is much more immunogenic than apoptotic cell death, it leads to inflammatory response that triggers signals that lead to dendritic cell (DC) stimulation and maturation. Our results are equal to Zerbini et al who demonstrated efficient antigen loading following DC maturation which can be elicited locally by heat shock proteins (HSPs), release of cytokines, complements and other inflammatory mediators [18].

Gravante et al, has explained this extensive immunological reaction following RFA by release of "danger signals" which triggers adaptive $\mathrm{T}$-cell responses when an adequate antigen presenting cell (APC) activation is present. These danger signals consist mainly of HSPs which activates DC [12]. The thermal effect of RFA can skip its local effect to extend to nonspecific inflammatory stimulation induced by necrotic cells that might help to overcome immune tolerance or anergy towards the transplanted tumour configuring it as "in vivo tumour vaccination" as mentioned by Hansler et al. [19].

Our work is considered as a unique study for immunological aspect of PEI, since few papers are published in the literature to compare the effect of alcohol ablation therapy on the immunological milieu. 13 patients have received multiple sessions of PEI and have proved to be of significance in elevating CD4+ after ablation $(\mathrm{P}<0.001)$. Absolute alcohol kills tumor cells by direct cytotoxic effects, causing necrosis of the treated region. It diffuses rapidly into cells, causing cellular dehydration and protein denaturation with resultant coagulation necrosis. This is followed by a fibrotic reaction, thrombosis, and occlusion of small vessels [20]. This local effect could be a potent stimulus for the immune cells to attract them to the site of inflammations.

Our results are confirmed by Nakayama et al who has injected ethanol in combination with microwave therapy, interleukins and interferon to treat melanoma and $\mathrm{HCC}$, he has found an increase in the infiltration of $\mathrm{T}$ lymphocytes and natural killer (NK) cells into the ablated tissues, confirming that an immune response was elicited [21].

Regarding MWA group, both CD4+ and CD4/ CD8 ratio has significantly increases $(\mathrm{p}<0.001)$ which are parallel to studies of Dong and his colleagues who had a maximal response on the third day and he also noticed a lower rate of recurrence with high degree of infiltration [22].

Recent studies have proved the effectiveness of TACE in induction of apoptosis, which provides theoretical evidence at the molecular level for the therapeutic effect of TACE [23].In the present study, all the immunologic indicators were significantly changed. When compared with before treatment, in the TACE group, CD4+ cells and the $\mathrm{CD} 4 / \mathrm{CD} 8$ ratio markedly decreased and CD8+ cells increased, suggesting that immunologic function was compromised shortly after treatment. These results are extremely similar to other studies especially to the work of Guan and his colleagues who displayed the same results [13].

The discrepancy between the good clinical ablative power of TACE and the impairment of the immunity following the procedure could be explained by the fact that TACE affects blood vessels and lead to its occlusion which essentially could lead to decrease in the flow of the immune 
cells, also the toxic materials used in TACE could have a role in this significant change.

Funding: Non.

Conflicts of interest: The authors declare that there is no conflict of interest.

Ethical approval:Informed consent was taken from each patient. The research protocol was duly approved by the Ethical Committee of Faculty of Medicine, Mansoura University .

\section{REFERENCES}

1- Ferlay J, Shin HR, Bray F, Forman D, Mathers C, Parkin DM. Estimates of worldwide burden of cancer in 2008: GLOBOCAN 2008. Int J Cancer 2010; 127:2893-917.

2- El-Serag HB. Epidemiology of viral hepatitis and hepatocellular carcinoma. Gastroenterology 2012; 142:1264-73.

3- Katherine A, McGlynn, W. Thomas London. The Global Epidemiology of Hepatocellular Carcinoma: Present and Future. Clin Liver Dis 2011;15 223243.

4- Shu G, Zhao W, Yue L, Su H, Xiang M. Antitumor immunostimulatory activity of polysaccharides from Salvia chinensis Benth. J Ethnopharmacol. 2015; pii: S0378-8741(15)00224-X.

5- Altekruse SF, McGlynn KA, Dickie LA, Kleiner DE. Hepatocellular carcinoma confirmation, treatment, and survival in surveillance, epidemiology, and end results registries, 19922008. Hepatology 2012; 55:476-82.

6- Padhya KT, Marrero JA, Singal AG. Recent advances in the treatment of hepatocellular carcinoma. Curr Opin Gastroenterol 2013; 29:285-92.

7- Kagawa T, Koizumi J, Kojima S, Nagata N, Numata M, Watanabe N, et al. Transcatheter arterial chemoembolization plus radiofrequency ablation therapy for early stage hepatocellular carcinoma: comparison with surgical resection. Cancer 2010; 116: 3638-3644.

8- Korangy F, Höchst B, Manns MP, Greten TF. Immune responses in hepatocellular carcinoma. Dig Dis 2010; 28: 150-154.

9- Patel KR, Liu TC, Vaccharajani N, Chapman WC, Brunt EM. Characterization of inflammatory (lymphoepithelioma-like) hepatocellular carcinoma: a study of 8 cases. Arch Pathol Lab Med. 2014; 138(9):1193-202.

10- Ormandy LA, Hillemann T, Wedemeyer H, Manns MP, Greten TF, Korangy F. Increased populations of regulatory $\mathrm{T}$ cells in peripheral blood of patients with hepatocellular carcinoma. . Cancer Res 2005; 65: 2457-2464.
11- Alisa A, Ives A, Pathan AA, Navarrete CV, Williams R, Bertoletti A, et al. Analysis of CD4+ $\mathrm{T}$-cell responses to a novel alpha-feto-proteinderived epitope in hepatocellular carcinoma patients. Clin Cancer Res 2005; 11: 6686-94.

12- Gravante G, Sconocchia G, Ong SL, Dennison AR, Lloyd DM. Immunoregulatory effects of liver ablation therapies for the treatment of primary and metastatic liver malignancies. Liver Int 2009;

13- Guan HT, Wang J, Yang M, Song L, Tong XQ, Zou YH. Changes in immunological function after treatment with transarterial chemoembolization plus radiofrequency ablation in hepatocellular carcinoma patients. Chin Med J 2013; 126 (19).

14- Schueller G, Kettenbach J, Sedivy R, Stift A, Friedl J, Gnant M, et al. Heat shock protein expression induced by percutaneous radiofrequency ablation of hepatocellular carcinoma in vivo. Int J Oncol 2004; 24: 609-13.

15- Schueller G, Kettenbach J, Sedivy R, Bergmeister H, Stift A, Fried J, et al. Expression of heat shock proteins in human hepatocellular carcinoma after radiofrequency ablation in an animal model. Oncol Rep 2004; 12: 495-9.

16- El-Zanaty F, Way A. Egypt Demographic and Health Survey 2008. Egyptian: Ministry of Health. Cairo: El-Zanaty and Associates, and Macro International; 2009.

17- Lavanchy D. Evolving epidemiology of hepatitis C virus. Clin Microbiol Infect. 2011; 17(2):107115.

18- Zerbini A, Pilli M, Fagnoni F, Pelosi G, Pizzi MG, Schivazappa S, et al. Increased immune stimulatory activity conferred to antigenpresenting cells by exposure to antigen extract from hepatocellular carcinoma after radiofrequency thermal ablation. J Immunother 2008; 31: 271-82.

19- Hansler J, Wissniowski TT, Schuppan D, Witte A, Bernatik T, Hahn EG,et al. Activation and dramatically increased cytolytic activity of tumor specific $\mathrm{T}$ lymphocytes after radio-frequency ablation in patients with hepatocellular carcinoma and colorectal liver metastases. World J Gastroenterol 2006; 12: 3716-3721.

20- Lee MJ, Mueller PR, Dawson SL, Gazelle SG, Hahn PF, Goldberg MA, et al. Percutaneous ethanol injection for the treatment of hepatic tumors: indications, mechanism of action, technique, and efficacy. AJR Am J Roentgenol. 1995 ; 164(1):215-20. 
21- Nakayama J, KokubaH, Kobayashi J, Yoshida Y, Hori Y. Experimental approaches for the treatment of murine B16 melanomas of various sizes. II: injection of ethanol with combinations of beta-interferon and microwaval hyperthermia for B16 melanomas with a size of greater than 10 mm in diameter. J Dermatol Sci 1997;15: 82-8.

22- Dong BW, Zhang J, Liang P, Yu XL, Su L, Yu DJ, et al .Sequential pathological and immunologic analysis of percutaneous microwave coagulation therapy of hepatocellular carcinoma. Int $J$ Hyperthermia 2003; 19: 119-33.

23- Lu W, Li YH, He XF, Zhao JB, Chen Y, Mei QL. Necrosis and apoptosis in hepatocellular carcinoma following low-dose versus high-dose preoperative chemoembolization. Cardiovasc Intervent Radiol 2008; 31: 1133-1140.
Peer reviewers:Nadia Mohammad Elwan, Professor of Tropical Medicine, Faculty of Medicine, Tanta University, Egypt, Member of Supreme Council Promotion Committee for Tropical Diseases; Mohamed I Radwan, Assistant Professor of Tropical Medicine and HepatoGastroenterology, Faculty of Medicine , Zagazig University, Egypt.

Editor : Mohamed H Emara; Lecturer of Tropical Medicine, Faculty of Medicine, Zagazig University, Egypt. 